\title{
How job stress influences job performance among Chinese healthcare workers: a cross-sectional study
}

\author{
Jianwei Deng ${ }^{1,2}$, Yilun Guo ${ }^{1,2}$, Tengyang Ma ${ }^{1,2}$, Tianan Yang ${ }^{1,2^{*}}$ (D) and Xu Tian ${ }^{3^{*}}$
}

\begin{abstract}
Objectives: Public service motivation refers to the idea of commitment to the public service, pursuit of the public interest, and the desire to perform work that is worthwhile to society. This study investigates how challenge stress and hindrance stress influence job performance among healthcare workers in Chinese public hospitals. It has also examined the mediating effect of public service motivation.

Methods: Data of 1594 healthcare workers were obtained from typical public hospitals in eastern, central, and western China. To test our hypotheses, we used descriptive statistical analysis, correlation analysis, structural equation modeling, and subgroup analysis to investigate the sample.

Results: Challenge stress and hindrance stress were strongly correlated among healthcare workers in Chinese public hospitals ( $\beta=0.59 ; p<0.001$ ). Challenge stress was significantly positively associated with public service motivation $(\beta=0.14 ; p<0.001)$ and job performance $(\beta=0.13 ; p<0.001)$. Hindrance stress was significantly negatively associated with public service motivation $(\beta=-0.27 ; p<0.001)$ and job performance $(\beta=-0.08 ; p<0.05)$. Public service motivation was directly positively associated with job performance $(\beta=0.58 ; p<0.001)$, and it indirectly mediated the association between job stress and job performance.

Conclusions: This study provides important empirical evidence on the effects of job stress and public service motivation on job performance among healthcare workers in Chinese public hospitals. Job performance may be raised by limiting hindrance stress, which provides moderate challenge stress and increases public service motivation.
\end{abstract}

Keywords: Challenge stress, Hindrance stress, Public service motivation, Job performance, Quality of healthcare, Big data

\section{Introduction}

Job stress can be defined as an individual's response to external stimuli in the environment. Recent studies have indicated that job stress has a major effect on individual physiology, psychology, and behavior [1-3], e.g., job performance [4]. However, previous studies have mostly focused on the negative effects of job stress on performance [5], which argue that higher pressures can make individuals perform less effectively on tasks that call for tolerance and concentration [6], subsequently resulting in lower productivity and job quality [5]. Following the

\footnotetext{
* Correspondence: Tianan.Yang@bit.edu.cn; TianXu@cass.org.cn

${ }^{1}$ School of Management and Economics, Beijing Institute of Technology, Beijing 100081, China

${ }^{3}$ Institute of World Economics and Politics, Chinese Academy of Social

Sciences, Beijing 100732, China

Full list of author information is available at the end of the article
}

development of positive psychology, Cavanaugh indicates that job stress can be divided into two dimensions: hindrance stress and challenge stress [7]. Challenge stress refers to the job stress that individuals feel that they can overcome and that benefits their career development, such as job load, job responsibility, and time urgency. Meanwhile, hindrance stress refers to the stress that individuals feel they cannot overcome and that prevents their career development, such as role conflict, organizational politics, and work insecurity [8]. Although recent studies have paid attention to the positive effects of job stress, most of them have been theoretical and qualitative [9]. Therefore, this study examines the impact of hindrance stress and challenge stress on job performance among healthcare workers in Chinese public hospitals, which responds to the call for more studies on

(c) The Author(s). 2019 Open Access This article is distributed under the terms of the Creative Commons Attribution 4.0 International License (http://creativecommons.org/licenses/by/4.0/), which permits unrestricted use, distribution, and reproduction in any medium, provided you give appropriate credit to the original author(s) and the source, provide a link to the Creative Commons license, and indicate if changes were made. The Creative Commons Public Domain Dedication waiver (http://creativecommons.org/publicdomain/zero/1.0/) applies to the data made available in this article, unless otherwise stated. 
different types of job stress [10] and provides empirical evidence of the differences in the effects of these stresses on job performance.

Previous studies have shown that job stress can indirectly affect job performance through mediator variables. Job satisfaction is mainly considered as the mediator [11]. Indeed, few studies have examined the mediating effect of other specific motivation constructs that inspire individual performance [12]. For example, public service motivation (PSM) denotes the idea of commitment to the public service, pursuit of the public interest, and the desire to perform work that is worthwhile to society [13]. Unlike job satisfaction, which is often regarded as a work-related emotion variable, PSM is an intrinsic predisposition to do good for others and society [14]. Goleman indicates that emotions move us to goal achievement, while motives shape our desires and actions [15]. Previous studies have investigated the positive relationship between PSM, job satisfaction, and job performance $[16,17]$. It has also been found that when individuals are exposed to higher pressures, they will become less sensitive to others which is manifested in a decrease of helping and an increase in aggression $[6,18]$. Therefore, this study introduces PSM and explores the mediating role that it plays in the relationship between job stress and job performance, which contributes to the development of the study of the mediator between job stress and performance, and answers the call for more studies of the effect of PSM on other psychological constructs and work-related outcomes $[14,16]$.

Overall, this study focuses on the relationship between job stress, PSM, and job performance (Fig. 1). Furthermore, this study provides empirical evidence for methods to alleviate pressure, improving performance and public service quality among Chinese healthcare workers.

\section{Materials and methods Data source}

This study performed a cross-sectional analysis of data from 1594 healthcare workers (response rate 97.9\%) in public hospitals from eastern, central, and western China in 2017, after obtaining ethical approval and informed consents. Table 1 shows the demographic characteristics of participants. Chinese public hospitals deliver more than $85 \%$ of hospital care and play a leading role in providing medical services [19]. Consequently, we chose public hospitals as our research focus. The ratio of public hospitals in eastern, central, and western China is 3.7:3.3:3 [19]. Therefore, we intended to use this ratio to randomly select 35,24 , and 24 public hospitals respectively. Limited by realistic conditions, we have actually selected 33, 14, and 19 public hospitals from these regions. Additionally, to guarantee data integrity and objectivity, this study randomly selected between 7 and $12 \%$ of healthcare workers in target hospitals through work identification numbers. Besides, to test convergent and divergent validity in our survey, we used similar and opposite questions in the questionnaire to examine whether our respondents provide with the expected answers. The participants will be deleted if their answers were not consistent.

\section{Variables and instruments}

Job stress was measured with the challenge and hindrance-related self-reported stress (C-HSS) scale of 11 items [7]. For example, the item, "The amount of time I spend at work" (Table 2) evaluates challenge stress. Meanwhile, the item, "The degree to which politics rather than performance affects organizational decisions" evaluates hindrance stress. The C-HSS scale uses a five-point Likert scale $(1=$ no stress; $5=$ great stress $)$. Higher values indicate greater job stress. In this study, the C-HSS scale was shown to have high reliability $(\alpha=$ 0.92-0.81).

PSM was measured with a five-item scale developed by Coursey and Pandey [18]. For example, the item, "Making a difference in society means more to me than personal achievements" (Table 2) asks the respondents to rate their PSM on a scale from 1 (strongly disagree) to 5 (strongly agree). Higher values indicate greater PSM. In our research, this scale was shown to have high reliability $(\alpha=0.84)$.

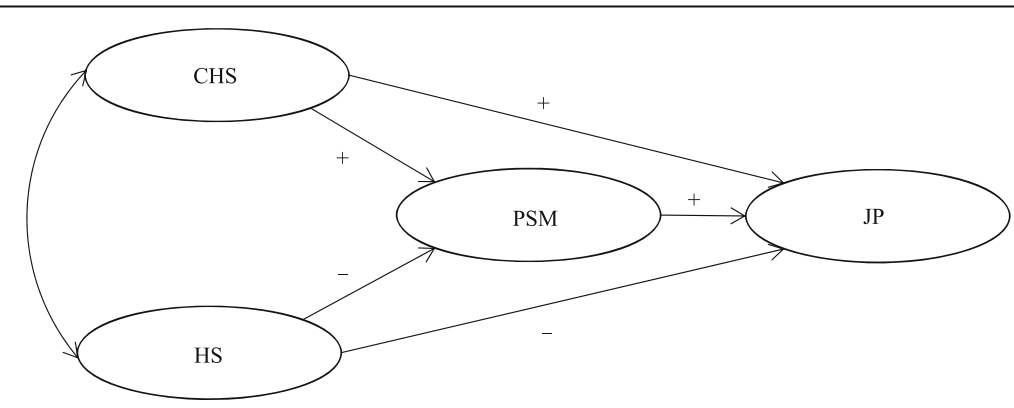

Fig. 1 Proposed model of how challenge stress (CHS), hindrance stress (HS), and public service motivation (PSM) influence job performance (JP) 
Table 1 Demographic characteristics of the sample

\begin{tabular}{|c|c|c|}
\hline Characteristics & Sample $(n=1594)$ & Percentage (\%) \\
\hline \multicolumn{3}{|l|}{ Sex } \\
\hline Male & 553 & 34.7 \\
\hline Female & 1007 & 63.2 \\
\hline \multicolumn{3}{|l|}{ Age (years) } \\
\hline-25 & 129 & 8.1 \\
\hline $25-30$ & 442 & 27.7 \\
\hline $31-35$ & 390 & 24.5 \\
\hline $36-40$ & 223 & 14.0 \\
\hline $41-45$ & 142 & 8.9 \\
\hline $46-50$ & 139 & 8.7 \\
\hline $51-55$ & 87 & 5.5 \\
\hline $56-60$ & 33 & 2.1 \\
\hline \multicolumn{3}{|l|}{ Position } \\
\hline Clinician & 722 & 45.3 \\
\hline Nurse & 523 & 32.8 \\
\hline Management & 88 & 5.5 \\
\hline Medical technicians & 143 & 9.0 \\
\hline Pharmacist & 54 & 3.4 \\
\hline \multicolumn{3}{|l|}{ Education } \\
\hline Under degree & 75 & 4.7 \\
\hline Junior college & 314 & 19.7 \\
\hline Undergraduate & 763 & 47.9 \\
\hline Master's & 305 & 19.1 \\
\hline Doctorate & 123 & 7.7 \\
\hline \multicolumn{3}{|l|}{ Title } \\
\hline Trainee & 665 & 41.7 \\
\hline Primary & 581 & 36.4 \\
\hline Middle & 205 & 12.9 \\
\hline Senior & 80 & 5.0 \\
\hline \multicolumn{3}{|l|}{ Seniority (years) } \\
\hline-3 & 313 & 19.6 \\
\hline $3-5$ & 335 & 21.0 \\
\hline $6-10$ & 347 & 21.8 \\
\hline $11-20$ & 303 & 19.0 \\
\hline $20-$ & 276 & 17.3 \\
\hline \multicolumn{3}{|l|}{ Department } \\
\hline Physician & 356 & 22.3 \\
\hline Surgery & 296 & 18.6 \\
\hline Obstetrics/gynecology & 190 & 11.9 \\
\hline Pediatrics & 159 & 10.0 \\
\hline Chinese medicine & 44 & 2.8 \\
\hline Emergency department/ICU & 91 & 5.7 \\
\hline Oncology & 31 & 1.9 \\
\hline Other clinical departments & 100 & 6.3 \\
\hline
\end{tabular}

Table 1 Demographic characteristics of the sample (Continued)

\begin{tabular}{lll}
\hline Characteristics & Sample $(n=1594)$ & Percentage (\%) \\
\hline Medical technology & 147 & 9.2 \\
Administration and logistics & 84 & 5.3 \\
Others & 67 & 4.2 \\
\hline Demographic information was missing for a few participants $(0.9-5.4 \%)$
\end{tabular}

Job performance was measured with a four-item scale that was developed by Darwish [20]. For example, the questions "Quality of your performance" and "How do you evaluate the performance of yourself at your job compared with your peers doing the same kind of work?" (Table 2) ask the respondents to rate their job performance on a scale from 1 (no good) to 5 (very good). Higher values indicate greater job performance. The self-appraisal of job performance as an evaluation device had been adopted by others and yielded acceptable outcomes [21, 22]. This scale was shown to have high reliability $(\alpha=0.86)$.

We also included individual characteristics, such as age, sex, education, job title, job experience, department, and seniority.

\section{Statistical analysis}

This study used SPSS 20.0 and AMOS 20.0 for the statistical analyses, which included descriptive analysis, correlation analysis, and path analysis. In structural equation modeling (SEM), the latent variables included challenge stress, hindrance stress, PSM, and job performance. All of these indicators were evaluated to determine if the model fit the data well. For example, when a criterion such as a root mean square error of approximation is less than 0.08 , and the normed fit index and comparative fit index are more than 0.90 , then the model has good global fit [23]. Before imputing these indicators into the model, we used correlation analysis to determine the significance of the correlations between challenge stress, hindrance stress, PSM, and job performance. SEM can identify effect relationships among variables, which are classified as direct or indirect [24]. Finally, we used the Sobel test to examine the significance of mediated effects [25].

To determine if the standardized regression coefficients $(\beta)$ differed by subgroup, we conducted subgroup analyses. To ensure that the subgroups were of equal size, the regions were classified as the eastern, central, and western. Hospital level was categorized as primary, secondary, and tertiary. Age was categorized as old (41 years or older), middle (31-40 years), and young (30 years or younger). Job title was classified as early career (trainee or entry-level worker) and $\mathrm{mid} / \mathrm{late}$ career (mid-level or senior worker). Gender was categorized as male and female. Post was classified as physician, nurse, 
Table 2 Mean (SD) for challenge stress (CHS), hindrance stress (HS), public service motivation (PSM), and job performance (JP) items

\begin{tabular}{|c|c|c|}
\hline Variable & Item & Mean \pm SD \\
\hline \multirow{6}{*}{$\begin{array}{l}\text { Challenge stress } \\
(1-6)\end{array}$} & CHS1. The number of projects and or assignments I have. & $3.49 \pm 0.82$ \\
\hline & CHS2. The amount of time I spend at work. & $3.52 \pm 0.81$ \\
\hline & CHS3. The volume of work that must be accomplished in the allotted time. & $3.44 \pm 0.88$ \\
\hline & CHS4. Time pressures I experience. & $3.48 \pm 0.88$ \\
\hline & CHS5. The amount of responsibility I have. & $3.63 \pm 0.89$ \\
\hline & CHS6. The scope of responsibility my position entails. & $3.50 \pm 0.85$ \\
\hline \multirow{5}{*}{$\begin{array}{l}\text { Hindrance stress } \\
(1-5)\end{array}$} & HS1. The degree to which politics rather than performance affects organizational decisions. & $2.87 \pm 1.09$ \\
\hline & HS2. The inability to clearly understand what is expected of me on the job. & $2.35 \pm 1.04$ \\
\hline & HS3. The amount of red tape I need to go through to get my job done. & $3.10 \pm 1.03$ \\
\hline & HS4. The lack of job security I have. & $3.06 \pm 1.13$ \\
\hline & HS5. The degree to which my career seems "stalled." & $3.01 \pm 1.03$ \\
\hline \multirow{5}{*}{$\begin{array}{l}\text { PSM } \\
(1-5)\end{array}$} & PSM1. Meaningful public service is very important to me. & $3.98 \pm 0.77$ \\
\hline & PSM2. I am often reminded by daily events about how dependent we are on one another. & $3.88 \pm 0.80$ \\
\hline & PSM3. Making a difference in society means more to me than personal achievements. & $3.74 \pm 0.85$ \\
\hline & PSM4. I am prepared to make sacrifices for the good of society. & $3.41 \pm 0.96$ \\
\hline & PSM5. I am not afraid to go to bat for the rights of others, even if it means I will be ridiculed. & $3.45 \pm 0.91$ \\
\hline \multirow{4}{*}{$\begin{array}{l}\text { Job performance } \\
(1-4)\end{array}$} & JP1. Quality of your performance. & $3.80 \pm 0.67$ \\
\hline & JP2. Your productivity on the job. & $3.86 \pm 0.70$ \\
\hline & $\begin{array}{l}\text { JP3. How do you evaluate the performance of your peers at their jobs compared with yourself } \\
\text { doing the same kind of work? }\end{array}$ & $3.88 \pm 0.68$ \\
\hline & $\begin{array}{l}\text { JP4. How do you evaluate the performance of yourself at your job compared with your peers } \\
\text { doing the same kind of work? }\end{array}$ & $3.86 \pm 0.69$ \\
\hline
\end{tabular}

and other (e.g., management, medical technician, and pharmacist). Seniority was classified as less than 5 years (employed for less than 5 years) and greater than 5 years (employed for longer than 5 years).

\section{Results}

Mean (SD) of challenge stress, hindrance stress, PSM, and job performance

Table 2 shows the results, including mean (M) and SD for challenge stress, hindrance stress, PSM, and job performance items. The means for the challenge stress items were higher than those for hindrance stress items. The means of challenge stress ranged from 3.44 $(\mathrm{SD}=$ $0.88)$ to $3.63(\mathrm{SD}=0.89)$. The means of hindrance stress ranged from $2.35(\mathrm{SD}=1.04)$ to $3.10(\mathrm{SD}=1.03)$. The means for the five PSM items were high, and the range was moderate. The means ranged from $3.41(\mathrm{SD}=0.96)$ to $3.98(\mathrm{SD}=0.77)$. The means for the four job performance items were relatively high, and the range was minor. The means ranged from $3.80(\mathrm{SD}=0.67)$ to 3.88 $(\mathrm{SD}=0.68)$.

Tables 3 and 4 show that among different regions, hospital levels, and demographic characteristics of healthcare workers, the values of challenge stress, hindrance stress, PSM, and job performance are discrepant. For example, the challenge stress was significantly higher in eastern public hospitals $(\mathrm{M}=3.54, \mathrm{SD}=0.70)$ and tertiary hospitals $(M=3.59, S D=0.67)$. In terms of hindrance stress,

Table 3 The differences in challenge stress (CHS), hindrance stress (HS), public service motivation (PSM), and job performance (JP) between different regions and hospital levels

\begin{tabular}{|c|c|c|c|c|c|c|c|c|}
\hline \multirow[t]{2}{*}{ Variable } & \multicolumn{3}{|l|}{ Region } & \multirow[t]{2}{*}{$p$} & \multicolumn{3}{|l|}{ Hospital level } & \multirow[t]{2}{*}{$p$} \\
\hline & Eastern $(n=1153)$ & Central $(n=201)$ & Western $(n=240)$ & & Primary $(n=284)$ & Secondary $(n=383)$ & Tertiary $(n=927)$ & \\
\hline $\mathrm{CHS}$ & $3.54(0.70)$ & $3.37(0.65)$ & $3.51(0.83)$ & $* *$ & $3.32(0.72)$ & $3.46(0.79)$ & $3.59(0.67)$ & $* * *$ \\
\hline HS & $2.89(0.78)$ & $2.84(0.82)$ & $2.83(0.91)$ & - & $2.86(0.78)$ & $2.81(0.89)$ & $2.91(0.77)$ & - \\
\hline PSM & $3.71(0.68)$ & $3.59(0.63)$ & $3.72(0.67)$ & - & $3.65(0.63)$ & $3.60(0.65)$ & $3.74(0.69)$ & $* * *$ \\
\hline$J P$ & $3.85(0.58)$ & $3.86(0.53)$ & $3.84(0.59)$ & - & $3.82(0.56)$ & $3.84(0.56)$ & $3.86(0.59)$ & - \\
\hline
\end{tabular}

Numbers outside parentheses are mean values; numbers inside parentheses are SD values

${ }^{* * *} p<0.001,{ }^{* *} p<0.01,{ }^{*} p<0.05$ 


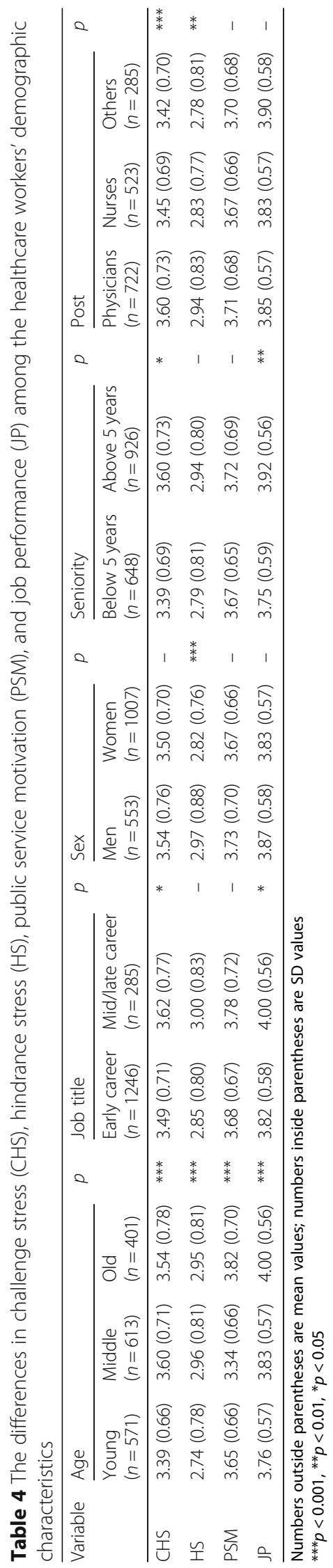


healthcare workers who were middle-aged $(\mathrm{M}=2.96$, $\mathrm{SD}$ $=0.81)$, male $(\mathrm{M}=2.97, \mathrm{SD}=0.88)$, and physicians $(\mathrm{M}=$ $2.94, \mathrm{SD}=0.83$ ) had a higher level of hindrance stress. With respect to PSM, the participants who were old $(\mathrm{M}=$ $3.82, \mathrm{SD}=0.70)$ or working in tertiary hospitals $(\mathrm{M}=3.74$, $\mathrm{SD}=0.69)$ performed at a higher level of PSM. The job performance was significantly higher among the participants who were old $(\mathrm{M}=4.00, \mathrm{SD}=0.56)$, who had worked for over 5 years $(\mathrm{M}=3.92, \mathrm{SD}=0.56)$, and who had a more senior job title $(M=4.00, S D=0.56)$.

\section{Correlations between challenge stress, hindrance stress, PSM, and job performance}

Table 5 shows the correlation coefficients $(r)$ that explained the positive correlations between items within the same construct. Hindrance stress was significantly inversely correlated with job performance and PSM $(r=-0.13$ to -0.17$)$. Challenge stress was significantly positively correlated with job performance $(r=0.06)$ but was not significantly correlated with PSM. There were also significant positive correlations both between PSM and job performance $(r=0.51)$, and between challenge stress and hindrance stress $(r=0.47)$.

\section{SEM}

In the final model, job stress was directly and significantly associated with PSM and job performance. Challenge stress was significantly positively associated with $\operatorname{PSM}(\beta=0.14 ; p<0.001)$ and job performance $(\beta=0.13$; $p<0.001)$. Hindrance stress was significantly inversely associated with PSM $(\beta=-0.27 ; p<0.001)$ and job performance $(\beta=-0.08 ; p<0.05)$. PSM was significantly positively associated with job performance $(\beta=0.58$; $p<$ $0.001)$. There was also a direct positive association between challenge stress and hindrance stress $(\beta=0.59 ; p$ $<0.001$ ). Challenge stress, hindrance stress, and PSM explained $37 \%$ of the variability in job performance. The criteria for fitness indicated that the revised model was more appropriate (Fig. 2).

We then noted significant indirect effects of challenge stress (Sobel $z=2.06 ; p<0.05$ ) and hindrance stress (Sobel $z=-6.07 ; p<0.001$ ) on job performance, which were both significantly mediated by PSM.

Table 5 Intercorrelations between challenge stress (CHS), hindrance stress (HS), public service motivation (PSM), and job performance (JP) items

\begin{tabular}{llllll}
\hline Variables & Mean (SD) & WP & CHS & HS & PSM \\
\hline JP & $3.85(0.58)$ & 1 & & & \\
CHS & $3.51(0.72)$ & $.06^{*}$ & 1 & & \\
HS & $2.88(0.81)$ & $-.13^{* *}$ & $.47^{* *}$ & 1 & \\
PSM & $3.69(0.67)$ & $.51^{* *}$ & -.02 & $-.17^{* *}$ & 1 \\
\hline
\end{tabular}

$N=1594 ; * * p<0.01,{ }^{*} p<0.05$
Tables 6 and 7 show the results of subgroup analyses. The impact of challenge stress on PSM was significant among the participants who were female $(\beta=0.20 ; p<$ $0.001)$, nurses $(\beta=0.27 ; p<0.001)$, and working in eastern $(\beta=0.17 ; p<0.001)$ or tertiary hospitals $(\beta=0.17 ; p$ $<0.001)$. Meanwhile, the hindrance stress did not significantly affect PSM among old $(\beta=-0.12 ; p>0.05)$ and $\mathrm{mid} /$ late career healthcare workers $(\beta=-0.36 ; p>0.05)$. Moreover, the effect of challenge stress on job performance was not significant among those working in the western region $(\beta=0.11 ; p>0.05)$ and primary hospital healthcare workers $(\beta=-0.02 ; p>0.05)$. The effect of hindrance stress on job performance was weaker than challenge stress, but between females $(\beta=-0.10 ; p<$ $0.05)$ and nurses $(\beta=-0.15 ; p<0.05)$ hindrance stress significantly inversely affected job performance.

\section{Discussion}

\section{Main finding of this study}

This study conducted a survey of 1594 Chinese healthcare workers from public hospitals to investigate the relationship between job stress, PSM, and job performance. Overall, the main findings are as follows.

Our first main finding is that the effect of different types of job stress on PSM is significant but diverse. As expected, hindrance stress adversely affects PSM. Previous studies have shown that hindrance stress could increase burnout [26], but very few studies have investigated the relationship between hindrance stress and PSM. Therefore, this study further confirms the negative impact of job stress, especially hindrance stress, on individuals and organizations. Meanwhile, this study enriches the antecedents research of PSM from the perspective of external environmental stimulus. Interestingly, our subgroup analysis showed that hindrance stress has a very strong inhibitory effect on PSM among Chinese healthcare workers in public hospitals, which may relate to the complexity of the healthcare environment. First, job stress among Chinese healthcare workers is extremely high [27] and they also have health problems at work [28], which further affect their emotional well-being and behaviors [29]. Second, Chinese healthcare workers are extremely overworked and they earn lower incomes compared to their counterparts in Europe and the USA [8]. The imbalance between giving and gain could restrain the PSM of Chinese healthcare workers [30]. Finally, the frequent occurrence of violence against Chinese healthcare workers leads to a lack of job security [31, 32]. Unfair promotion and career advancement in Chinese public hospitals also hinders career development among Chinese healthcare workers [33]. All of these factors aggravate hindrance stress and limit PSM. 


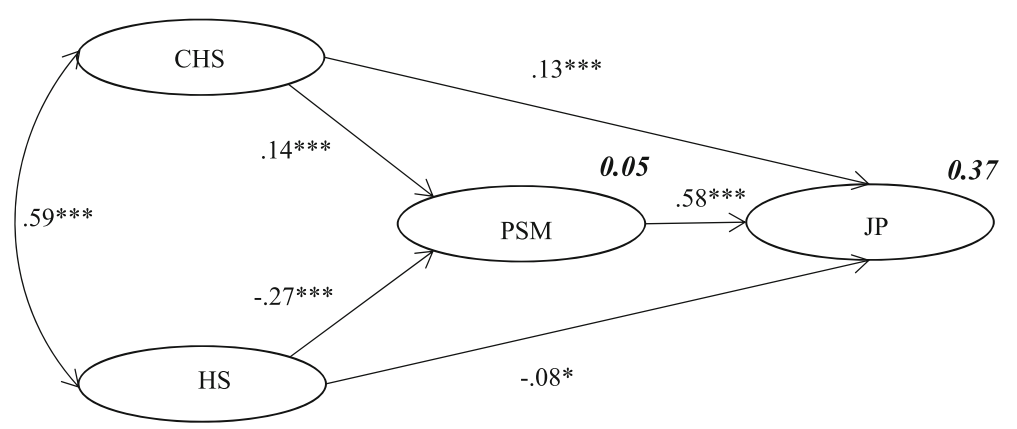

Fig. 2 Final model illustrating how challenge stress (CHS), hindrance stress (HS), and public service motivation (PSM) influence job performance (JP) (numbers not in bold are standardized regression coefficients, and numbers in bold explain variability; chi-square, 974.925; degrees of freedom, 160, $p<0.001$; root mean square error of approximation, 0.057; normed fit index, 0.943 ; comparative fit index, 0.952 ; ${ }^{* * *} p<0.001,{ }^{* *} p<0.01,{ }^{*} p<0.05$ )

In this study, we found that challenge stress is significantly positively associated with PSM among Chinese healthcare workers, which is in agreement with most previous studies. Therefore, this study further explores the effect of challenge stress in Chinese public hospitals and it provides empirical support for studies of the positive impact of job stress [34]. Interestingly, our subgroup analysis showed that the impact of challenge stress on PSM was significant among those participants who were working in eastern or tertiary hospitals, females, and nurses. The challenge stress of healthcare workers was significantly higher in eastern public hospitals and tertiary hospitals. Eastern region has more adequate medical resources as the most economically developed region in China [19]. However, based on this, the competition between hospitals in the eastern region is also increasing [35]. In addition, the reform of public hospitals has been a top priority since 2009 and, therefore, tertiary hospitals that play a dominant role in health delivery need to establish an effective and efficient system to deliver more cost-effective and higher-quality services [36]. In this case, it is necessary for hospitals in the eastern region and tertiary hospitals to continuously stimulate healthcare workers to improve the quality of public services and meet their development needs, such as job titles, honors, and benefits [37]. Thus, to achieve better career development, the increase in competition among healthcare workers has stimulated the positive effect of challenge stress. Nevertheless, the impact of challenge stress on PSM was significant among females and nurses, which may relate to staff composition and the nurses' job characteristics. Nurses are mostly women, and the whole nursing process is actually individualized care [38]. Driven by high work responsibilities through longer and more frequent contact with patients, nurses will tend to show a higher level of compassion and caring for patients, and this will promote their PSM.

Our second key finding is that PSM significantly and positively affects job performance among Chinese healthcare workers. Although many studies have found that PSM has a positive impact on individuals and organizations $[39,40]$, recent studies suggest that PSM also has a dark side [41, 42]. Therefore, the impact of PSM on individuals remains controversial. We suggest that the different work environments lead to different reactions. Furthermore, some studies have found that the positive effects of PSM can change over time, particularly in hostile working conditions [39]. Consequently, this study examined the effect of PSM in Chinese public hospitals and supports the view that PSM has a positive impact on individuals and organizations. Healthcare workers with high levels of PSM can fit better with the

Table 6 Standardized regression coefficients ( $\beta$ ) with $p$ values for the components of subgroup analyses between different regions and hospital levels

\begin{tabular}{|c|c|c|c|c|c|c|}
\hline \multirow[t]{2}{*}{ Path } & \multicolumn{3}{|l|}{ Region } & \multicolumn{3}{|l|}{ Hospital level } \\
\hline & Eastern $(n=1153)$ & Central $(n=201)$ & Western $(n=240)$ & Primary $(n=284)$ & Secondary $(n=383)$ & Tertiary $(n=927)$ \\
\hline CHS to PSM & $0.17^{* * *}$ & -0.07 & 0.13 & -0.01 & $0.07(0.392)$ & $0.17^{* * *}$ \\
\hline HS to PSM & $-0.31^{* * *}$ & 0.08 & $-0.37^{* * *}$ & $-0.29 * * *$ & $-0.28^{* *}$ & $-0.26^{* * *}$ \\
\hline PSM to JP & $0.60^{* * *}$ & $0.68^{* * *}$ & $0.46^{* * *}$ & $0.70^{* * *}$ & $0.42^{* * *}$ & $0.59^{* * *}$ \\
\hline CHS to JP & $0.13^{* * *}$ & $0.24^{*}$ & 0.11 & -0.02 & $0.27^{* * *}$ & $0.14^{* * *}$ \\
\hline HS to JP & $-0.10^{*}$ & $-0.22^{*}$ & 0.03 & 0.05 & $-0.27^{* * *}$ & -0.05 \\
\hline $\mathrm{CHS}$ to HS & $0.59^{* * *}$ & $0.67^{* * *}$ & $0.45^{* * *}$ & $0.47^{* * *}$ & $0.56^{* * *}$ & $0.60^{* * *}$ \\
\hline
\end{tabular}




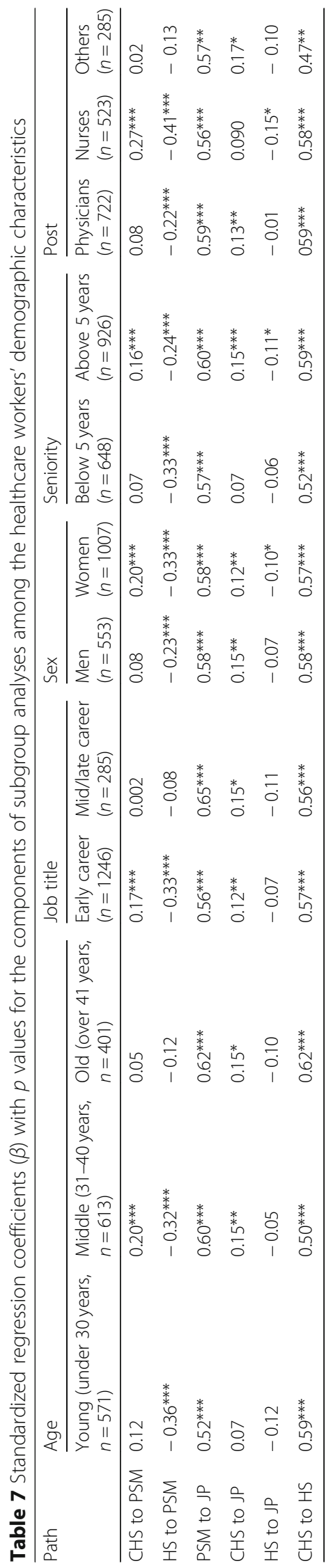


values of the hospitals. They will then perform better to achieve their own values. This finding shows that to develop the positive effect of PSM, managers should try to ameliorate the working environment and psychological status of healthcare workers, such as reducing workplace violence [32] and demonstrating more social support [43].

Our third key finding is that challenge stress positively affects job performance while hindrance stress inversely affects job performance. This is in agreement with most previous studies, which have shown that challenge stress has a positive effect on job performance due to the individuals' positive response and hindrance stress as an excessive demand leads to poor job performance [8]. However, this study has shown that the effect of hindrance stress on job performance is weaker than the effect of challenge stress, which may be caused by the special nature of the work done by healthcare workers. As providers of medical services, the work efficiency and quality of healthcare workers are directly linked to public service quality, and even related to public health and safety. Therefore, although hindrance stress has a negative impact on job performance among healthcare workers, the effect is weaker than challenge stress. This finding suggests that policymakers should implement differential intervention pressure measures, focusing on the negative impact of hindrance stress, for example, by simplifying work processes and reforming pay structures. In addition, policymakers should fully utilize the positive effect of challenge stress through the establishment of reasonable work intensity [14] and reasonable shift work. However, it should be noted that excessive challenge stress, such as overload, may have negative effects on organizations and individuals [44]. Therefore, future studies should investigate ways to control challenge stress within a reasonable range. They should also define the critical points between challenge stress and hindrance stress. In addition, a previous study has argued that because a stressful workplace will not be easy to change, it is essential for healthcare workers to learn how to cope with job stress [29]. Given that job stress among Chinese healthcare workers is very high, policymakers should provide relevant training and guidance for healthcare workers through employee assistance programs.

Finally, this study finds that PSM indirectly mediates the association between job stress and job performance among Chinese healthcare workers, which can be explained by social exchange theory. In this study, the healthcare workers expect that lower hindrance stress and moderate challenge stress will promote career development, which should be provided by the hospitals. The public hospitals need enthusiastic service and good performance, which can be provided by the healthcare workers. Therefore, on the basis of the "reciprocity principle" [45], healthcare workers exchange low hindrance stress and moderate challenge stress by showing high levels of PSM and job performance. This study further explores the impact of job stress on job performance from the perspective of the individual internal driving force. It also enriches the mediating studies between job stress and job performance. According to our findings, policymakers should fully consider the effect of PSM. In particular, managers should optimize their staff recruitment and selection systems [46] to absorb individuals with a high level of PSM into the hospitals. They could also strengthen the organizational culture to achieve the best fit between individual and organizational values.

\section{Limitations and future directions}

This study has several limitations that deserve attention. First, this study was conducted through a cross-sectional survey. The relationship between challenge stress, hindrance stress, PSM, and job performance cannot be assumed to be causal and, therefore, it should be tested in future longitudinal studies. Second, we only recruited Chinese healthcare workers from public hospitals, and we excluded those healthcare workers from private hospitals. This restricts the generalizability and robustness of our conclusions. Although PSM is viewed as particularly salient in public organizations [47], it can also be found in the private sector [48]. Consequently, in the future, healthcare workers in private hospitals should be investigated to develop our hypothesis and models. Third, job performance was self-reported in our study. Consequently, the data might be subjective and positive. Future studies should add objective data into the study design to explore whether job stress or PSM affect job performance. Fourth, this study only explored the impact of job stress and PSM on job performance. This meant that we ignored other work-related outcomes, such as public service quality and organizational citizenship behavior. Therefore, it is recommended that future studies empirically investigate the relationship between job stress, PSM, and other work behaviors.

\section{Conclusion}

Although job stress has been a subject of constant concern, there is a lack of empirical research on the effects of different types of job stress on productivity-related outcomes [26]. Through a cross-sectional analysis of 1594 Chinse healthcare workers from public hospitals, this study has found that healthcare workers are the key to improving public service quality. However, they generally suffer from high levels of job stress and this is likely to inhibit their PSM and then leads to poor job performance. To improve job performance and public service quality, public hospital administrators should pay attention to the relationship between challenge stress, 
hindrance stress, PSM, and job performance. They should also focus on targeting interventions to improve work conditions and maintain a high level of PSM. In addition, it is important to help healthcare workers to effectively cope with hindrance stress, and hospitals should promote personal professional development.

\section{Abbreviations}

PSM: Public service motivation; SEM: Structural equation modeling

\section{Acknowledgments}

The authors thank research assistants in our representative hospitals for their support for the data collection in our study.

\section{Availability of data and material}

Please contact author for data requests.

\section{About the authors}

Jianwei Deng, PhD, Assistant Professor in the School of Management and Economics, Beijing Institute of Technology, Beijing, China (email:

111605@bit.edu.cn). He specializes in public service motivation, performance evaluation, and quality of health care.

Yilun Guo is a postgraduate student in the School of Management and Economics, Beijing Institute of Technology, Beijing, China (email:

18810776591@163.com). Her primary research interests are job stress, public service motivation, and human resource management.

Tengyang Ma is a postgraduate student in the School of Management and Economics, Beijing Institute of Technology, Beijing, China (email:

18829285968@163.com). Her main research interests are job stress, human resources development, and organizational behavior.

Tianan Yang, PhD, Associate Professor in the School of Management and Economics, Beijing Institute of Technology, Beijing, China (email: tianan.yang@bit.edu.cn; Tel: + 86-10-6891-8132). His primary research interests are job stress, health management, and industrial organizational psychology.

Tian Xu, PhD, Assistant Research Fellow of the Institute of World Economics and Politics, Chinese Academy of Social Sciences, Beijing, China (email: tianxu@cass.org.cn). His research focuses on International Political Economy, Democratic Theory, and Confucian Political Philosophy.

\section{Funding}

This study was supported by the National Science Funding of China (grant no. 71804009; 91746116; 71603018; 71432002), the MOE (Ministry of Education in China) Project of Humanities and Social Sciences (grant no. 16YJC630017), the Beijing Social Science Foundation (grant no. 17GLC043;17JDGLB008), the Beijing Natural Science Foundation of China (grant no. 9174042), the Beijing Excellent Talent Training Project (grant no. 2015000020124G047), Beijing Institute of Technology Research Fund Program for Young Scholars (grant no. 3210012261598), and the Special Fund for Joint Development Program of Beijing MunicipalCommission of Education

\section{Authors' contributions}

$J D, Y G, T M, T Y$ and $X T$ conceived of and designed the study. JD, YG, TM, TY, and $\mathrm{XT}$ contributed to the data collection, data management, statistical analysis, interpretation of the results, and revision of the manuscript. JD and YG wrote the paper. All authors reviewed the paper, provided significant feedback, and approved the final manuscript.

\section{Ethics approval and consent to participate}

All procedures performed in studies involving human participants were with ethics approval from an independent research ethics committee in China (No. KYX2016007).

\section{Consent for publication}

Not applicable.

\section{Competing interests}

The authors declare that they have no competing interests.

\section{Publisher's Note}

Springer Nature remains neutral with regard to jurisdictional claims in published maps and institutional affiliations.

\section{Author details}

${ }^{1}$ School of Management and Economics, Beijing Institute of Technology, Beijing 100081, China. ${ }^{2}$ Sustainable Development Research Institute for Economy and Society of Beijing, Beijing 100081, China. Institute of World Economics and Politics, Chinese Academy of Social Sciences, Beijing 100732, China.

Received: 27 July 2018 Accepted: 18 December 2018

Published online: 05 January 2019

\section{References}

1. Burke RJ, Greenglass ER. Hospital restructuring, work-family conflict and burnout among nursing staff. Psychol Health. 2001;16:583-94.

2. Gonge $H$, Jensen LD, Bonde JP. Are psychosocial factors associated with low back pain among nursing personnel? Work Stress. 2002;16:79-87.

3. Johnston M, Pollard B. Length of nurses' working shift: stress and information processing. In: Biondi C Psychology in Hospital. Rome, Nuova Editrice Spada; 1991. p. 101-5.

4. Motowidlo SJ, Manning MR. Occupational stress: its causes and consequences for job performance. J Appl Psychol. 1986;71:618-23.

5. Leveck ML, Jones CB. The nursing practice environment, staff retention and quality of care. Res Nurs Health. 1996;19:331-43.

6. Cohen S. After effects of stress on human performance and social behavior: a review of research and theory. Psychol Bull. 1980;88:82-108.

7. Cavanaugh MA, Boswell WR, Roehling MV, Boudreau JW. An empirical examination of self-reported work stress among U.S. managers. J Appl Psychol. 2000;85:65-74.

8. Yang T, Guo Y, Ma M, Li Y, Tian H, Deng J. Job stress and presenteeism among Chinese healthcare workers: the mediating effects of affective commitment. Int J Env Res Public Heal. 2017;14:978-89.

9. Bandura A. Social foundations for thought and action: a social cognitive theory. Englewood Cliffs: PrenticeHall; 1986.

10. Liou KT. The effect of professional orientation on job stress. Rev Public Pers Adm. 1994;14:52-63.

11. Nabirye RC, Katleen C. Occupational stress, job satisfaction and job performance among hospital nurses in Kampala, Uganda. J Nurs Manag. 2011;19:760-8.

12. Aninany GA, Howard N, John EW, Apam B, Helen P, Svetla L, Eunice KK, Easmon O. Can performance-based incentives improve motivation of nurses and midwives in primary facilities in northern Ghana? A quasi-experimental study. Glob Health Action. 2016;9:1-10.

13. Scott PG, Pandey SK. Red tape and PSM findings from a national survey of managers in state health and human services agencies. Rev Public Pers Adm. 2005;25:155-80.

14. Lin L, Siu OL, Shi K, Bai XW. Challenge and hindrance job demands, job resource, and their relationships with vigor and emotional exhaustion. Int Confer Manag Sci Eng. 2009;29:14-6.

15. Goleman D. Emotional intelligence. New York: McGraw-Hill; 2000.

16. Palma R, Sepe E. Structural equation modelling: a silver bullet for evaluating PSM. Qual Quant. 2017;51:729-44.

17. Taylor J. Organizational influences, PSM, and work outcomes: an Australian study. Int Public Manag J. 2008;11:67-88.

18. Coursey D, Pandey SK. PSM and support for citizen participation: a test of Perry and Vandenabeele's reformulation of PSM theory. Public Adm Rev. 2012;72:572-82.

19. NHFP Commission. China health and family planning statistical digest. Beijing: Peking Union Medical College Press; 2015.

20. Darwish AY. Organizational commitment: a mediator of the relationships of leadership behavior with job satisfaction and performance in a non-western country. J Manag Psychol. 2000;15:6-28.

21. Stevens JM, Beyer JM, Trice HM. Assessing personal role and organizational predictors of managerial commitment. Acad Manag J. 1978;21:380-96.

22. Somers MJ, Birnbaum D. Assessing self-appraisal of job-performance as an evaluation device - are the poor results a function of method or methodology. Hum relat. 1991;44:1081-91.

23. Bollen KA, Long JS. Testing structural equation models. Bull Soc Meth. 1993; 23:66-7. 
24. Hu LT, Bentler PM. Fit indices in covariance structure modeling: sensitivity to models. Sociol Methodol. 1998;13:290-312.

25. Mackinnon DP, Lockwood CM, Hoffman JM, West SG, Sheets V. A comparison of methods to test mediation and other intervening variable effects. Psychol Methods. 2002;7:83-97.

26. Liu B, Yang K, Yu W. Work-related stressors and health-related outcomes in public service: examining the role of PSM. Am Rev Public Adm. 2014;3:1-24.

27. Zhang $X Q$, Wang $H Q$, Chen $X Y$. A survey of medical staffs in China. Sci Technol Rev. 2009;27:118-9.

28. Goetzel RZ, Long SR, Ozminkowski RJ. Health, absence, disability, and presenteeism cost estimates of certain physical and mental health conditions affecting U.S. employers. J Occup Environ Med. 2004;46:398-412.

29. Yang T, Zhu M, Chen Q, Liu Y, Deng J. Is the global occupational stress equally addressed? A systematic literature review on effective stress interventions. Evid-based Med Public Health. 2016:2:1-33.

30. Bakker AB. A job demands-resources approach to public service motivation. Public Adm Rev. 2015;75:723-32.

31. Itzhaki M, Bluvstein I, Bortz AP, Kostistky H, Noy DB, Filshtinsky V, et al. Mental health nurse's exposure to workplace violence leads to job stress, which leads to reduced professional quality of life. Front Psychiatry. 2018;9: $59-68$.

32. Lancet T. Violence against doctors: why China? Why now? What next? Lancet. 2014;383:1013.

33. Huang Y, Chen J, Lin P, Lin Z, Jiang Y. Female doctor's work stressors and relationship with their mental health. J Chin Prev Med. 2012;13:55-8.

34. Wallace JC, Edwards BD, Arnold T, Frazier ML, Finch DM. Work stressors, role-based performance, and the moderating influence of organizational support. J Appl Psychol. 2009;94:254-67.

35. Pan J, Qin X, Li Q, Messina JP, Delamater PL. Does hospital competition improve health care delivery in China? China Econ Rev. 2015;33:179-99.

36. Li L, Fu H. China's health care system reform: progress and prospects. Int J Health Plann Mgmt. 2017;32:240-53.

37. Millar R, Chen Y, Wang M, Fang L, Liu J. It's all about the money? A qualitative study of healthcare worker motivation in urban China. Int J Equity Health. 2017;16:120-31.

38. Lo W, Chien L, Hwang F, Huang N, Chiou S. From job stress to intention to leave among hospital nurses: a structural equation modelling approach. J Adv Nurs. 2017;74:677-88.

39. Kim S. Factors affection state government information technology employee turnover intentions. Am Rev Public Adm. 2004;35:137-56.

40. Vandenabeele $\mathbf{W}$. The mediating effect of job satisfaction and organizational commitment on self-reported performance: more robust evidence of the PSM-performance relationship. Int Rev Adm. 2009;75:11-34.

41. Giauque D, Ritz A, Varone F, Anderfhren S. Resigned but satisfied: the negative impact of public service motivation and red tape on work satisfaction. Public Adm. 2012;90:175-93.

42. Grant AM, Campbell EM. Doing good, doing harm, being well and burniong out: the interactions of perceived prosocial and antisocial impact in service work. J Occup Organ Psychol. 2007:80:665-91.

43. Abualrub RF. Job stress, job performance, and social support among hospital nurses. J Nurs Scholarsh. 2004;36:73-8.

44. Yang T, Ma M, Zhu M, Liu Y, Chen Q, Zhang S, et al. Challenge or hindrance: does job stress affect presenteeism among Chinese healthcare workers? J Occup Health. 2018;60:163-71.

45. Gouldner AW. The norm of reciprocity: a preliminary statement. Am Sociol Rev. 1960;25:161-78.

46. Arson FB, Allan J, Johnston D, Johnston M, Choudhry C, Jones M. Stress amongst nurses working in a healthcare telephone-advice service: relationship with job satisfaction, intention to leave, sickness absence, and performance. J Adv Nurs. 2012;68:1624-35.

47. Vandenabeele W. Government calling: PSM as an element in selecting government as an employer of choice. Public Adm. 2008:86:1089-105.

48. Taylor J. PSM, civic attitudes, and actions of public, nonprofit, and private sector employees. Public Adm. 2010;88:1083-98.

Ready to submit your research? Choose BMC and benefit from:

- fast, convenient online submission

- thorough peer review by experienced researchers in your field

- rapid publication on acceptance

- support for research data, including large and complex data types

- gold Open Access which fosters wider collaboration and increased citations

- maximum visibility for your research: over $100 \mathrm{M}$ website views per year

At BMC, research is always in progress.

Learn more biomedcentral.com/submissions 